\title{
Assessment Cognitive Functions Among Elderly Patients Attending Out Patient Clinics in Assiut University Hospital
}

\author{
Heba M. Fahmy, Hoda D. Fahmy, Alaa El-Din M. Darweesh \& Asmaa G. Mohammed. \\ Assistant lecturer of Geriatric Nursing, Geriatric Nursing Department, Faculty of Nursing, Assiut University Egypt. \\ Professor of Community Health Nursing, Community Health Nursing department, Faculty of Nursing, Assiut \\ University Egypt. \\ Professor of Psychiatry, Psychiatry Medicine Department, Faculty of Medicine, Assiut University Egypt. \\ Assistance Professor of Community Health Nursing, Community Health Nursing Department, Faculty of Nursing, \\ Assiut University Egypt.
}

\begin{abstract}
Cognitive impairment is common among older adults. It doesn't not only threaten their quality of life but also has a negative impact on caregivers, as well as represents challenges in different clinical care settings. The aim of the study assess cognitive functions and identify the prevalence of cognitive impairment among elderly patients attending outpatient clinics in Assiut University Hospital. Material and Methods: the study included 580 elderly patients recruited from outpatient clinics of Assiut University Hospital, aged 60 years and older, they were selected by none- probability quota sample from the first of July 2012 until the end of June 2013 screened by Mini-Mental State Examination (MMSE) for cognitive functions, they also were assessed for their sociodemographic characteristics, health habits and Activities of Daily Living (ADL). Results: The present study shows that $18.8 \%$ of elderly patients had cognitive impairment, $57.8 \%$ of elderly with cognitive impairment have no leisure activities, and $7.3 \%$ of them were found to be totally dependent in ADL. Conclusion: elderly patients at high risk to develop cognitive impairment especially those who are aged $\geq 65$ years, female, live in rural area, not educated, lives alone and have impairment in ADL. Recommendations: screening for cognitive impairments among the elderly is important in early detection for those with cognitive impairments.
\end{abstract}

Keywords: Elderly, Cognitive Functions \& Cognitive Impairment.

\section{Introduction}

Older people are the fastest growing segment of the population worldwide. Globally, the number of persons aged 60 years and more is expected to almost triple within the next few decades, from 672 million in 2005 to nearly 1.9 billion by the year 2050 (PerelLevin, 2008).

The cognitive function begins to decline from the age of 50 and accelerates after the age of 65 years. Cognitive impairment is common among elderly and increases with aging. (Angevaren et al., 2008 \& Fossati et al., 2011). It does not only threaten the quality of life of older people but also has a negative impact on their caregivers, as well as representing challenges in different clinical care settings (Sweed \& Elawam, 2010). Conditions in which cognitive functioning is impaired include dementia, Alzheimer's, delirium, and depression (American Psychiatric Association, 2000).

Cognitive function is also influenced by other conditions like female sex, low education, a clinical history of stroke, tobacco smoking, alcohol consumption, physical inactivity, depression, and lack of social support (Anstey et al., 2007, Fossati et al., 2011).

Early recognition of cognitive impairment is important for the diagnosis of potentially reversible medical conditions, and initiation of treatment interventions. Patients and caregivers will have time to prepare for lifestyle changes and plan for the future (Miller, 2009, Sweed \& Elawam, 2010).

Nurse practitioners who work in a variety of practice settings commonly provide care to the older adults with varying levels of cognitive ability. Although nurses are trained to recognize and provide care to patients with dementia, it is also important to recognize patients who are experiencing mild cognitive impairment (Elliott et al., 2008).

\section{Significance of the study}

Cognitive impairment including dementia is a growing worldwide public health problem, and its prevalence in elderly persons is between $10 \%$ and 22\% (Etgen et.al., 2010). In Egypt, the prevalence of cognitive impairment was $20.9 \%$ among residents of the elderly homes in Cairo (Sweed \& Elawam, 
2010). The prevalence of dementia was $4.5 \%$ in Assuit governorate-Egypt (Farrag et al., 1998), and in Sharkia governorate, was $3.66 \%$ (Zaitoun et al., 2008).

\section{Aim of the study}

To assess cognitive functions and identify the prevalence of cognitive impairment among the elderly patients.

\section{Materials \& Method}

\section{Research design}

The cross-sectional descriptive research design was used in this study.

\section{Study Setting}

This study was conducted at out patient's clinics (i.e. ophthalmology, diabetes, cardiology, internal medicine clinics) in Assiut University Hospital.

Data was collected on average of two days weekly; with an average number of 3-4 elderly interviewed per day during the assessment of their cognitive functions, the approximate time spent on filling the questionnaire sheet was around 30 minutes for filling of the structured interview questionnaire.

\section{Study sample}

The participants were recruited during the period from the first of July 2012 until the end of June 2013 and their number were 580 elderly patients aged 60 years and above. Non- probability quota sample technique was used in the present study.

\section{Inclusion criteria}

- Elderly patients aged 60 years and more of both sexes who were attended outpatient clinics (i.e. ophthalmology, diabetes, cardiology, internal medicine clinics) of Assiut University Hospital.

- Able to communicate.

- Accept to participate in the study.

Exclusion criteria

- Elderly patients which have cognitive disorders.

Tools of the study: Three tools were used for data collection

1: Structured interview questionnaire sheet:

A specially designed sheet was used for data collection. It was based on relevant literature in order to assess cognitive function among elderly patients. It included four parts:

Part I: it included sociodemographic characteristics as age, sex, marital status, education, occupation, residence, social assistance, family size, and family type.

Part II: it included questions to assess elder's health habits as nutrition, sleep, smoking, alcohol consumption, exercises, leisure activities and social activities.
Part V: assessment of medical history including diabetes mellitus, hypertension, cardiovascular disease, arteriosclerosis or other diseases.

Part VI: the presence of family history suggesting cognitive impairment in any family member.

\section{2-The Mini-mental status examination} (MMSE)(Folstein et. al., 1975)

The Mini-Mental State Examination (MMSE) is a widely used, well-validated screening tool for evaluation of cognitive impairment. The MMSE was used to assess cognitive function.

Assessment of the cognitive status by using the Arabic version of the Mini-Mental state examination (MMSE). It briefly measures orientation to time and place $($ score $=10)$, short-term verbal memory (score $=3$ ), attention and calculation (score $=5)$, immediate recall (score $=3$ ), and language (score $=9$ ). The total score of MMSE is 30, a score less than 24/30 indicates cognitive impairment among educated people and less than 22/30 among illiterate subjects.

3- Independence in Activities of Daily Living (ADL) (Katz et. al., 1970):

Index of Independence in Activities of Daily Living (ADL) was used to assess the ability to carry out the basic daily living activities which include; bathing, dressing, toileting, sphincter control, feeding, and transfer. Each criteria is graded according to level of dependence of the elderly patient; either performs independently (score=2), performs with assistance (partial dependent) $($ score $=1)$, or unable to perform (dependent) $($ score $=0)$. Total score of 0-5 indicates completely dependent, 6-9 partially dependent, and 10-12 independent

Pilot study

A pilot study was carried out before starting data collection on (10 elderly patients), who were not included in the study. The aim of the pilot study is to test the clarity and applicability of the tool and to assess the respondent's acceptance and understanding of the questions, and the needed modifications were performed.

\section{Ethical considerations}

The study was approved by the ethical committee of Faculty of Nursing Assiut University. Oral consent from elderly patients for participation in the study was obtained. Full explanation about the purpose of the study was discussed with the patients before starting data collection. Confidentiality of the information was maintained during the steps of the study. No harm to the participant was expected during all steps of the study. Patient was informed about the result of the test.

VI- Statistical analysis

The obtained data were reviewed, prepared for computer entry, coded, analyzed and tabulated. 
Descriptive statistics (frequencies, percentage, and mean) were done using computer program SPSS version16. Chi-square test, independent sample t-test, paired samples t-test, were used for analysis of variance.

\section{Results}

Table (1): Distribution of the elderly patients regarding their demographic characteristics $(n=580)$.

\begin{tabular}{|c|c|c|}
\hline \multirow{2}{*}{ Socio demographic characteristics } & \multicolumn{2}{|c|}{ Total $(n=580)$} \\
\hline & No. & $\%$ \\
\hline \multicolumn{3}{|l|}{ Age } \\
\hline $60<65$ years & 404 & 69.7 \\
\hline$\geq 65$ years & 176 & 30.3 \\
\hline Mean \pm SD & \multicolumn{2}{|c|}{$63.00 \pm 4.95$} \\
\hline \multicolumn{3}{|l|}{ Sex } \\
\hline Male & 186 & 32.1 \\
\hline Female & 394 & 67.9 \\
\hline \multicolumn{3}{|l|}{ Residence } \\
\hline Urban & 104 & 17.9 \\
\hline Rural & 476 & 82.1 \\
\hline \multicolumn{3}{|l|}{ Marital status } \\
\hline Single & 4 & 0.7 \\
\hline Married & 371 & 64.0 \\
\hline Widow & 205 & 35.3 \\
\hline \multicolumn{3}{|l|}{ Education } \\
\hline Not educated & 516 & 89.0 \\
\hline Educated & 64 & 11.0 \\
\hline \multicolumn{3}{|l|}{ Current occupation } \\
\hline Farmer & 126 & 21.7 \\
\hline Skilled worker & 14 & 2.4 \\
\hline Non-skilled work & 19 & 3.3 \\
\hline Housewife & 391 & 67.4 \\
\hline Retired & 30 & 5.2 \\
\hline \multicolumn{3}{|l|}{ Social assistance } \\
\hline Yes & 156 & 26.9 \\
\hline No & 424 & 73.1 \\
\hline \multicolumn{3}{|l|}{ Living condition } \\
\hline Lives alone & 67 & 11.6 \\
\hline Lives with their family & 513 & 88.4 \\
\hline \multicolumn{3}{|l|}{ Family type $($ no=513) } \\
\hline Nuclear & 99 & 19.3 \\
\hline Extended & 414 & 80.7 \\
\hline \multicolumn{3}{|l|}{ Family history of cognitive impairment } \\
\hline Yes & 44 & 7.6 \\
\hline No & 536 & 92.4 \\
\hline
\end{tabular}


Table (2): Distribution of elderly patients according to their total score of different domains of Mini Mental State Examination (MMSE).

\begin{tabular}{|l|c|c|c|c|}
\hline \multicolumn{1}{|c|}{ MMSE Domains } & $\begin{array}{c}\text { Male } \\
(\mathbf{n = 1 8 6 )}\end{array}$ & $\begin{array}{c}\text { Female } \\
(\mathbf{n = 3 9 4 )}\end{array}$ & $\begin{array}{c}\text { Total } \\
(\mathbf{n = 5 8 0})\end{array}$ & \multirow{2}{*}{ P-value } \\
\cline { 2 - 5 } & Mean \pm SD & Mean \pm SD & Mean \pm SD & \\
\hline Orientation (time and place) & $8.9 \pm 1.5$ & $7.7 \pm 1.9$ & $8.1 \pm 1.9$ & $0.000^{*}$ \\
\hline Registration (short-term verbal memory) & $2.9 \pm 0.4$ & $2.9 \pm 0.5$ & $2.9 \pm 0.5$ & 0.576 \\
\hline Attention and calculation & $4.8 \pm 0.9$ & $4.7 \pm 1.2$ & $4.7 \pm 1.1$ & 0.179 \\
\hline immediate Recall & $2.2 \pm 1.0$ & $2.0 \pm 1.1$ & $2.1 \pm 1.1$ & $0.020^{*}$ \\
\hline Language & $6.4 \pm 1.0$ & $6.0 \pm 0.7$ & $6.1 \pm 0.8$ & $0.000^{*}$ \\
\hline Total score of MMSE & $25.3 \pm 3.2$ & $23.3 \pm 3.6$ & $23.9 \pm 3.6$ & $0.000^{*}$ \\
\hline
\end{tabular}

${ }^{(*)}$ There is a Significant Difference

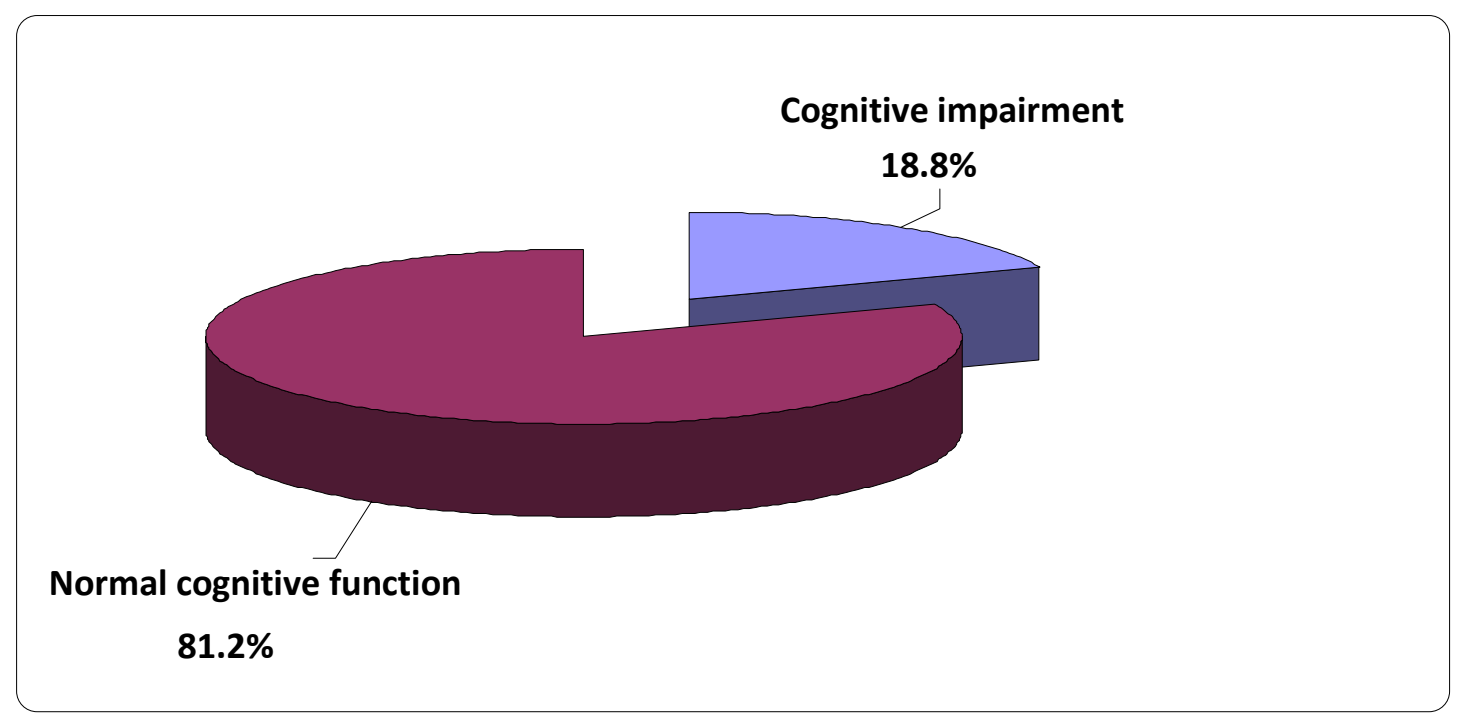

Fig. (1): Distribution of elderly patients according to their cognitive functions.

Table (3): Relationship between sociodemographic characteristics of elderly with cognitive impairment and those with normal cognitive functions $(\mathbf{n}=\mathbf{5 8 0})$.

\begin{tabular}{|c|c|c|c|c|c|c|}
\hline \multirow[t]{2}{*}{$\begin{array}{l}\text { Socio-demographic } \\
\text { characteristic }\end{array}$} & \multicolumn{2}{|c|}{$\begin{array}{c}\text { Elderly with cognitive } \\
\text { impairment } \\
(n=109)\end{array}$} & \multicolumn{2}{|c|}{$\begin{array}{c}\text { Elderly with normal } \\
\text { cognitive functions } \\
(\mathbf{n}=471)\end{array}$} & \multirow[t]{2}{*}{$\mathbf{X}^{2}$} & \multirow[t]{2}{*}{ P-value } \\
\hline & No. & $\%$ & No. & $\%$ & & \\
\hline \multicolumn{5}{|l|}{ Age } & \multirow{3}{*}{2.56} & \multirow{3}{*}{0.109} \\
\hline$<65$ years $(n=404)$ & 69 & 17.1 & 335 & 82.9 & & \\
\hline$\geq 65$ years $(n=176)$ & 40 & 22.7 & 136 & 77.3 & & \\
\hline \multicolumn{5}{|l|}{ Sex } & \multirow{3}{*}{14.91} & \multirow{3}{*}{$0.000 *$} \\
\hline Male $(n=186)$ & 18 & 9.7 & 168 & 90.3 & & \\
\hline Female $(n=394)$ & 91 & 23.1 & 303 & 76.9 & & \\
\hline \multicolumn{5}{|l|}{ Residence } & \multirow{3}{*}{3.29} & \multirow{3}{*}{0.070} \\
\hline Urban $(n=104)$ & 13 & 12.5 & 91 & 87.5 & & \\
\hline Rural $(n=476)$ & 96 & 20.2 & 380 & 79.8 & & \\
\hline \multicolumn{5}{|l|}{ Education } & \multirow{3}{*}{11.57} & \multirow{3}{*}{$0.001 *$} \\
\hline Not educated(n=516) & 107 & 20.7 & 409 & 79.3 & & \\
\hline Educated $(n=64)$ & 2 & 3.1 & 62 & 96.9 & & \\
\hline
\end{tabular}




\begin{tabular}{|c|c|c|c|c|c|c|}
\hline \multirow[t]{2}{*}{$\begin{array}{l}\text { Socio-demographic } \\
\text { characteristic }\end{array}$} & \multicolumn{2}{|c|}{$\begin{array}{c}\text { Elderly with cognitive } \\
\text { impairment } \\
(n=109)\end{array}$} & \multicolumn{2}{|c|}{$\begin{array}{c}\text { Elderly with normal } \\
\text { cognitive functions } \\
(n=471)\end{array}$} & \multirow[t]{2}{*}{$\mathbf{X}^{2}$} & \multirow[t]{2}{*}{ P-value } \\
\hline & No. & $\%$ & No. & $\%$ & & \\
\hline \multicolumn{5}{|l|}{ Living condition } & \multirow{3}{*}{7.82} & \multirow{3}{*}{$0.005 *$} \\
\hline Lives alone $(\mathrm{n}=67)$ & 21 & 31.3 & 46 & 68.7 & & \\
\hline Lives with family $(n=513)$ & 88 & 17.2 & 425 & 82.8 & & \\
\hline
\end{tabular}

${ }^{(*)}$ There is a significant difference

Table (4): Health habits of elderly with cognitive impairment and those with normal cognitive functions $(n=580)$.

\begin{tabular}{|c|c|c|c|c|c|c|}
\hline \multirow[t]{2}{*}{ Health habits } & \multicolumn{2}{|c|}{$\begin{array}{l}\text { Elderly with cognitive } \\
\text { impairment }(n=109)\end{array}$} & \multicolumn{2}{|c|}{$\begin{array}{c}\text { Elderly with normal cognitive } \\
\text { functions }(n=471)\end{array}$} & \multirow[t]{2}{*}{$\mathbf{X}^{2}$} & \multirow{2}{*}{$\begin{array}{c}\text { P- } \\
\text { value }\end{array}$} \\
\hline & No. & $\%$ & No. & $\%$ & & \\
\hline \multicolumn{5}{|l|}{$\overline{\text { Smoking }}$} & \multirow{3}{*}{4.83} & \multirow{3}{*}{$0.028 *$} \\
\hline Smoker $(n=53)$ & 4 & 7.5 & 49 & 92.5 & & \\
\hline Non-smoker $(n=527)$ & 105 & 19.9 & 422 & 80.1 & & \\
\hline \multicolumn{5}{|l|}{ Drinking coffee/ tea } & \multirow{3}{*}{2.22} & \multirow{3}{*}{0.136} \\
\hline Yes $(n=436)$ & 88 & 20.2 & 348 & 79.8 & & \\
\hline No $(n=144)$ & 21 & 14.6 & 123 & 85.4 & & \\
\hline \multicolumn{5}{|c|}{ History of sleep disturbance } & \multirow{3}{*}{0.811} & \multirow{3}{*}{0.368} \\
\hline Yes $(n=409)$ & 73 & 17.8 & 336 & 82.2 & & \\
\hline No $(n=171)$ & 36 & 21.1 & 135 & 78.9 & & \\
\hline \multicolumn{5}{|l|}{ Leisure activities } & \multirow{3}{*}{42.13} & \multirow{3}{*}{ 0.000* } \\
\hline Yes $(n=396)$ & 46 & 11.6 & 350 & 88.4 & & \\
\hline No $(n=184)$ & 63 & 34.2 & 121 & 65.8 & & \\
\hline \multicolumn{5}{|c|}{ Sharing in social activities } & \multirow{3}{*}{4.46} & \multirow{3}{*}{$0.035 *$} \\
\hline Yes $(n=287)$ & 44 & 15.3 & 243 & 84.7 & & \\
\hline No $(n=293)$ & 65 & 22.2 & 228 & 77.8 & & \\
\hline
\end{tabular}

${ }^{(*)}$ There is a significant difference

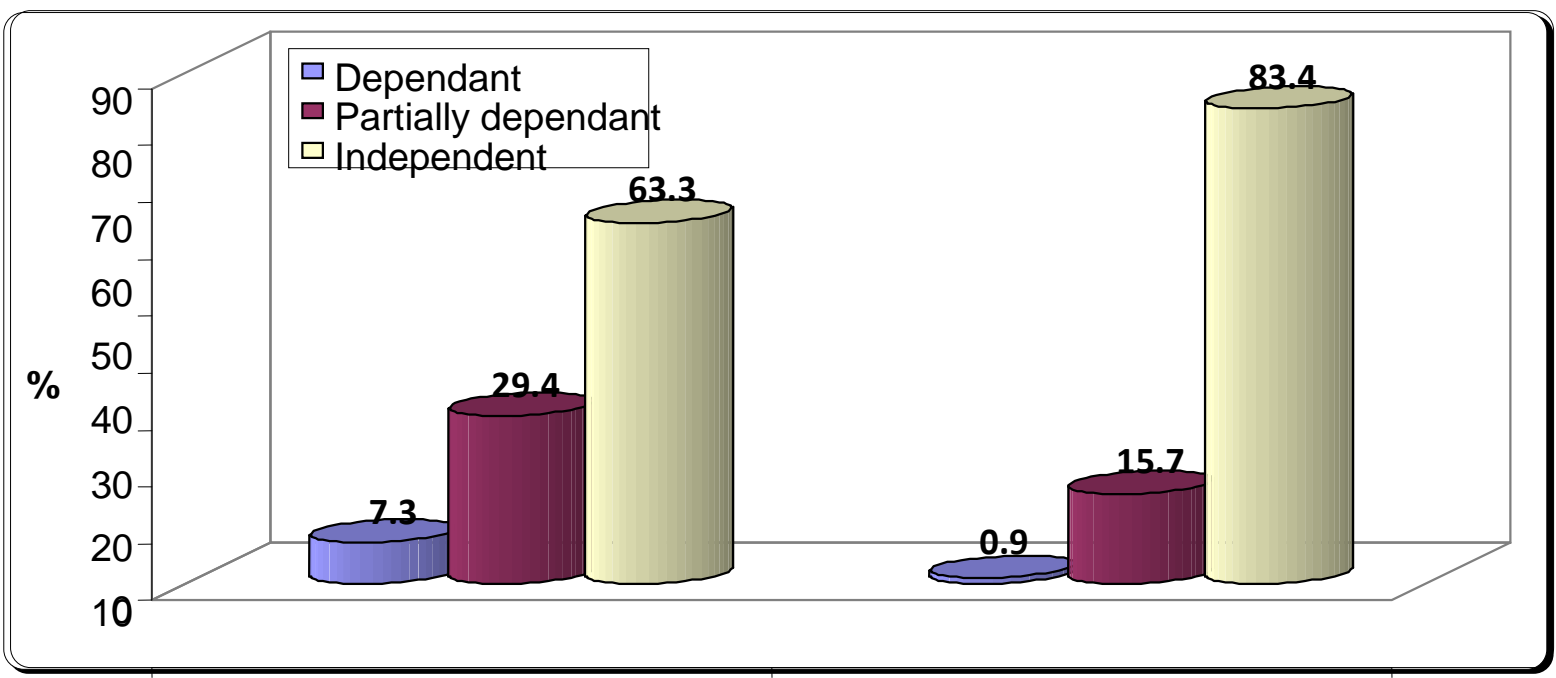

\section{Cognitive impairment}

Normal cognitive function

$P=0.028^{*}$

Figure (2) Relationship between cognitive functions and Activity of Daily Living (ADL) of elderly patients $(\mathbf{n}=\mathbf{5 8 0})$. 
Table (5): Relationship between cognitive functions of elderly patients and their medical diagnosis in outpatient clinics at Assiut University Hospital (n=580).

\begin{tabular}{|c|c|c|c|c|c|c|}
\hline \multirow[t]{2}{*}{ Medical Diagnosis } & \multicolumn{2}{|c|}{$\begin{array}{c}\text { Cognitive impairment } \\
\qquad(n=109)\end{array}$} & \multicolumn{2}{|c|}{$\begin{array}{c}\text { Normal cognitive } \\
\text { functions } \\
(n=471)\end{array}$} & \multirow[t]{2}{*}{$\mathbf{X}^{2}$} & \multirow[t]{2}{*}{ P-value } \\
\hline & No. & $\%$ & No. & $\%$ & & \\
\hline Internal medicine Clinic: $(n=214)$ & 37 & 17.3 & 177 & 82.7 & & \\
\hline Liver cirrhosis $(n=53)$ & 10 & 18.9 & 43 & 81.1 & 0.12 & 0.726 \\
\hline Colitis $(n=31)$ & 7 & 22.6 & 24 & 77.4 & 0.71 & 0.400 \\
\hline Hepatitis $(n=29)$ & 2 & 6.9 & 27 & 93.1 & 2.53 & 0.111 \\
\hline Peptic ulcer $(n=26)$ & 3 & 11.5 & 23 & 88.5 & 0.69 & 0.582 \\
\hline Renal failure $(n=23)$ & 5 & 21.7 & 18 & 78.3 & 0.36 & 0.760 \\
\hline Anemia $(n=18)$ & 2 & 11.1 & 16 & 88.9 & 0.16 & 0.690 \\
\hline${ }^{\infty}$ Other $(n=34)$ & 8 & 23.5 & 26 & 76.5 & 1.10 & 0.294 \\
\hline Ophthalmology Clinic: $(n=171)$ & 43 & 25.1 & 128 & 74.9 & & \\
\hline Cataract $(n=119)$ & 30 & 25.2 & 89 & 74.8 & 0.01 & 0.977 \\
\hline Glaucoma $(n=26)$ & 7 & 26.9 & 19 & 73.1 & 0.05 & 0.821 \\
\hline Retinal detachment $(\mathrm{n}=10)$ & 2 & 20.0 & 8 & 80.0 & 0.00 & 0.991 \\
\hline Eye inflammation $(\mathrm{n}=16)$ & 4 & 25.0 & 12 & 75.0 & 0.00 & 0.989 \\
\hline Cardiology Clinic: $(n=117)$ & 16 & 13.7 & 101 & 86.3 & & \\
\hline Hypertension $(n=39)$ & 7 & 17.9 & 32 & 82.1 & 0.91 & 0.341 \\
\hline Angina $(n=26)$ & 5 & 19.2 & 21 & 80.8 & 0.37 & 0.541 \\
\hline Myocardial infraction $(n=16)$ & 0 & 0.0 & 16 & 100.0 & 1.75 & 0.186 \\
\hline Atherosclerosis $(\mathrm{n}=28)$ & 1 & 3.6 & 27 & 96.4 & 2.16 & 0.142 \\
\hline Rheumatic heart disease $(n=4)$ & 1 & 25.0 & 3 & 75.0 & 0.00 & 0.449 \\
\hline Hypotension $(n=4)$ & 2 & 50.0 & 2 & 50.0 & 1.99 & 0.158 \\
\hline \multicolumn{7}{|l|}{ Diabetes Clinic: $(n=78)$} \\
\hline Diabetes mellitus & 13 & 16.7 & 65 & 83.3 & & -- \\
\hline
\end{tabular}

$\infty$ Other Diseases: Renal Stones, Cholitisystis, Splenomegaly, Osephygel Varese, \& Prostatic Enlargement.

Table (1): Distribution of the elderly patients regarding to their demographic characteristics, it was observed that the mean age of the studied sample was $63.0 \pm 4.95$ years, $67.9 \%$ of them were females, $82.1 \%$ of them live in the rural area, $64.0 \%$ of them were married, $89.0 \%$ of them were not educated, $21.7 \%$ of them were farmer, $73.1 \%$ of them don't receive social assistance, $88.4 \%$ of them were living with their family and $71.9 \%$ of them were living in extended family. Only $7.6 \%$ of the total sample had a family history of cognitive impairment.

Table (2): Distribution of elderly patients according to their total score of different domains of MiniMental State Examination (MMSE), it showed that the mean total score of (MMSE) of the whole sample were $23.9 \pm 3.6$, and female have significantly lower mean of total score $(23.3 \pm 3.6)$ than male $(25.3 \pm$ 3.2).

Figure (1): Distribution of elderly patients according to their cognitive functions, it was observed that as regards cognitive functions, $81.2 \%$ of the studied sample had normal cognitive functions. While $18.8 \%$ of them had cognitive impairment.
Table (3): Relationship between sociodemographic characteristics of elderly with cognitive impairment and those with normal cognitive functions, it showed that significant higher percentage of cognitive impaired elderly patients was female $(23.1 \%)$, not educated $(20.7 \%)$, and lives alone $(31.3 \%)$.

Table (4): Health habits of elderly with cognitive impairment and those with normal cognitive functions, it was observed that significant higher percentage of cognitive impaired elderly patients was not smoker (19.9\%), have no leisure activities $(34.2 \%)$ and not sharing in social activities (22.2\%).

Figure (2): Relationship between cognitive functions and Activity of Daily Living (ADL) of elderly patients, it was observed that $7.3 \%$ of the cognitively impaired were found to be totally dependent in activities of daily living (ADL) compared to $0.9 \%$ of those with normal cognitive functions.

Table (5): Relationship between cognitive functions of elderly patients and their medical diagnosis, it was observed that $17.3 \%$ of elderly patients who attended Internal medicine clinic have cognitive impairment (18.9\% of them have liver cirrhoses, $22.6 \%$ have 
colitis and $21.7 \%$ have renal failure), and $25.1 \%$ of elderly patients who attended Ophthalmology clinic have cognitive impairment $(25.2 \%$ of them have cataract patients and $26.9 \%$ have glaucoma).

\section{Discussion}

Cognitive impairment is common among older adults. In the present study, the researcher assesses cognitive functions and determine the prevalence of cognitive impairment among elderly people. Regarding sociodemographic characteristics of the studied population, it was found that their mean age was $63.00 \pm 4.95$ years, $67.9 \%$ was females, $82.1 \%$ were living in the rural areas, $64.0 \%$ of them were married, $89.0 \%$ were not educated, $64.0 \%$ were a housewife, and $11.6 \%$ lived alone.

These results are similar to that reported by the study conducted by Shehatah et al., (2009) who studied the prevalence of depression and association of cognitive impairment in elderly in suburban community in Egypt and reported that the mean age of participants was $66.16 \pm 5.62$ years, $52.3 \%$ were females and $47.7 \%$ were males, $67.4 \%$ were married, $89.5 \%$ were not educated, and $16.3 \%$ lived alone.

Also, the study illustrated that the mean score of MMSE of the participants was $23.93 \pm 3.58$, which is still within normal range of MMSE score. However it tends to be at the lower limit of normal range which is expected in relation to the educational level of participants as $89.0 \%$ of them were not educated. This score was reported by Sweed \& Elawam (2010)

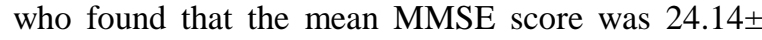
4.48 in their studied population in an elderly home in Cairo.

It was shown from the present study that the prevalence of cognitive impairment was $18.8 \%$ (MMSE score less than 23). This was in agreement with Sweed \& Elawam (2010) who found the slightly higher prevalence of cognitive impairment (20.9\%). Also, the present study agreed with Wu et al., (2011) who studied socio-demographic and health-related factors associated with cognitive impairment in the elderly in Taiwan and found that the prevalence of cognitive impairment was $22.2 \%$.

The higher prevalence rates of cognitive impairment which found in present study and the other studies may be explained by; first, the prevalence of cognitive impairment increases with aging, and our sample in this study was elderly patients whose age 60 years and older, and second due to increasing the impairment in ADL of the elderly patients, and increase prevalence of chronic illness among elderly patients as, hypertension, diabetes mellitus, and sensory impairment (visual and hearing impairment) that might affect cognitive functions.
Cognitive impairment is usually common among older adults. Cognitive function is influenced by other factors like female sex, low education, a clinical history of stroke, tobacco smoking, physical inactivity, and lack of social support (Fossati et al., 2011).

It was shown from the present study that increased age, being female, living in rural area, not educated, being single, lived alone, have a history of sleep disturbance, have no leisure activities, and no sharing in social activities were associated with lower MMSE scores (cognitive impairment).

This agreed with Wu et al., (2011) who found that low level of education, being single, low social support, physical inactivity, non-coffee drinking and poor physical function were associated with a higher risk of cognitive impairment. Also, it was agreed with Zhuang et al., (2012) who found that associated factors to lower MMSE scores: low education, old age, marital status, and limited physical. Also, it was agreed with Sweed \& Elawam (2010) who reported that increasing age, being female, and being illiterates were associated with lower MMSE score.

The present study agreed with Verghese et al., (2003) who studied leisure activities and the risk of dementia in the elderly, and found that participation in leisure activities is associated with a reduced risk of dementia. Also was agreed with Krueger et al., (2009) who studied social engagement and cognitive function in old age, and found that higher level of social engagement in old age is associated with the better cognitive function.

The relation between cognitive impairment and aging can be interpreted by that, with aging the age-related changes of the brain lead to a decrease of cognitive functions and lowering the MMSE score. Cognitive impairment was higher among females than males in the present study could be explained by that $67.9 \%$ of studied sample were female, and all of the elderly females didn't have any work.

The relation between the low level of education and risk of cognitive impairment can be explained as; a higher brain reserve capacity of educated persons could postpone the onset of cognitive impairment. The educated elderly may get more brain stimulation. Factors related to education such as lifestyle, occupational exposure, morbidity, and health care might play a role. Persons with higher educational levels are more resistant to the effects of dementia as a result of having a greater cognitive reserve and increased the complexity of neuronal synapses.

The relation between living in rural area and risk of cognitive impairment can be explained as; in a rural community, there is lacking or inadequate in health care and mental health resources, lacking in social facilities and increase the rate of illiteracy. 
The relation between leisure activities and risk of cognitive impairment can be explained as leisure activities affect MMSE score as leisure activities like cognitive activities (e.g. reading, playing board games, and playing musical instruments) were associated with a lower risk of cognitive impairment. Participation in leisure activities may increase cognitive reserve, delaying and slowing the pathological processes of disease (cognitive impairment). Leisure activities and exercises have beneficial effects on the brain by promoting plasticity, increasing the levels of neurotrophic factors in the brain, and enhancing resistance to insults.

The present study illustrates that as regarding to the relation between cognitive functions state of elderly patients and their Activity of Daily Living (ADL), the current study found $7.3 \%$ of the cognitively impaired were found to be totally dependent in activities of daily living (ADL) compared to $0.9 \%$ of those with normal cognitive functions. It was reported by many authors that cognitive impairment has a significant effect on ADL, either those who live in the nursing home (Ang et al., 2006, Sweed \& Elawam, 2010) or those who live in their home (Mehta et al., 2002).

Cognitive impairment can be demonstrated by performance decline in activities of daily living (ADL) and it is closely correlated with mental status scores. The increasing prevalence of chronic illness among elderly patients can affect on their ADL.

Major risk factors e.g. hypertension and diabetes mellitus, known to be associated frequently with different cerebrovascular diseases that might also have a contribution in degenerative forms of cognitive impairment (Cicconetti et al., 2004).

Regarding medical diseases of an elderly patient with cognitive function, the present study shows that $17.9 \%$ of them have hypertension, $16.7 \%$ have diabetes mellitus, $25.2 \%$ of having cataract patients and $26.9 \%$ have glaucoma.

This result is similar to that reported by the study conducted by Umegaki et al., (2012) who studied risk factors associated with cognitive decline in the elderly with type 2 diabetes, and found that diabetes mellitus and hypertension were significantly associated with cognitive declines. Also, Maggi et al., (2009) studied diabetes as a risk factor for cognitive decline in older patients and found that diabetes consider as a risk factor for cognitive decline in older patients, as the metabolic and cardiovascular abnormalities associated with diabetes might be responsible for the cognitive decline, at different rates and ages, in men and women.

The relationship between cognitive impairment and hypertension is explained as chronic hypertension leads to the breakdown of cere bro capillaries, which lead to cognitive impairment.

The relationship between cognitive impairment and diabetes mellitus is explained as diabetes (hyperglycemia) was considered associated risk factor for cognitive impairment and related to the high metabolic demand for energy in the brain, and even small disturbance in glucose metabolism can affect cognitive performance and can lead to cognitive impairment.

In agreement with Gussekloo et al., (2005) who studied the sensory impairment and cognitive functioning in oldest-old subjects, and found visual impairment were associated with lower scores on the MMSE. Also agrees with Ong et al., (2012) who study visual impairment, age-related eye diseases, and cognitive function, and found that older persons with visual impairment, particularly those due to cataract, were more likely to have cognitive dysfunction.

The relationship between cognitive impairment and visual impairment is based on the influence of visual impairment on the level and quality of interactive experiences of older adults, thus reducing their capacity to develop and maintain relationships and to participate in activities that may improve their physical, mental and psychosocial well-being. Vision impairment affects cognitive performance by reducing the level of participation in these types of stimulating activities and thus leads to a decrease in brain reserve. The lack of activity may exacerbate cognitive impairment indirectly if it predisposes a person to depression and social isolation.

\section{Conclusion}

Elderly patients at high risk to develop cognitive impairment especially those who are aged $\geq 65$ years, female, live in rural area, not educated, lives alone and have impairment in ADL.

\section{Recommendations}

screening for cognitive impairments among the elderly is very important in early detection for those with cognitive impairments. Increasing elderly awareness about the importance of regular examinations to detect early medical disorders that may negatively affect cognitive functions.

\section{References}

1. American Psychiatric Association (APA), (2000): Diagnostic and statistical manual of mental disorders, $4^{\text {th }}$ ed., Washington

2. Ang Y., Au S.., Yap L.., \& Ee C., (2006): Functional decline of the elderly in a nursing home. Singapore Med J. 47(3):219-224. 
3. Angevaren M., Aufdemkampe G., Verhaar H., Aleman A., \& Vanhees L., (2008): Physical activity and enhanced fitness to improve cognitive function in older people without known cognitive impairment. Cochrane Database Syst. Rev. 3, CD005381.

4. Anstey K., Von-Sanden C., Salim A., \& O'Kearney R., (2007): Smoking as a risk factor for dementia and cognitive decline: a metaanalysis of prospective studies. Am. J. Epidemiol. 166, Pp. 367-378.

5. Cicconetti P., Riolo N., Priami C., Tafaro L., ands Ettore E., (2004): Risk factors for cognitive impairment, Recenti Prog Med. Nov;95(11):535-45.

6. Elliott A., Horgas A., \& Marsiske M., (2008): Nurses' Role In Identifying Mild Cognitive Impairment In Older Adults, Geriatr Nurs.; 29(1): Pp. 38-47.

7. Etgen T., Sander D., Huntgeburth U., Poppert H., Förstl H., and Bickel H., (2010): Physical Activity and Incident Cognitive Impairment in Elderly Persons, Arch Intern Med., 170(2): Pp. 186-193.

8. Farrag A., Farwiz H., Khedr E., \& Mahfouz R., (1998): Prevalence of Alzheimer's disease and other dementing disorders: in Assiut-Upper Egypt Study. Dement and Geriatr Cogn Disord.; 9: Pp 322-8.

9. Folstein M., Folstein S., \& McHugh P., (1975): Mini-Mental State: A practical method for grading the cognitive state of patients for the clinician. J Psychiat Res 12: Pp. 189-198.

10. Fossati C., De Benedetto G., Leboffe C., Marigliano B., Mancinella M., Ettorre E., and Marigliano V., (2011): A self-administered questionnaire to screen the risk of dementia: A pilot study and the results of a comparison with the mini-mental state examination (MMSE), Archives of Gerontology and Geriatrics, 1-5.

11. Gussekloo J., de Craen A., Oduber C., van Boxtel M., \& Westendorp R., (2005): Sensory impairment and cognitive functioning in oldestold subjects: the Leiden 85+ Study. Am J Geriatr Psychiatry.; 13(9): Pp. 781-6.

12. Katz S., Downs T., Cash H., \& Grotz R., (1970): Progress in development of the index of ADL. Gerontologist; 10(1): Pp. 20-30.

13. Krueger K., Wilson R., Kamenetsky J., Barnes L., Bienias J., \& Bennett D., (2009): Social Engagement And Cognitive Function In Old Age, Exp Aging Res.; 35(1): Pp. 45-60.

14. Maggi S., Limongi F., Noale M., Romanato G., Tonin P., Rozzini R., Scafato E., \& Crepaldi G., (2009): Diabetes as a risk factor for cognitive decline in older patients. Dement Geriatr Cogn Disord.;27(1): Pp. 24-33.

15. Mehta K., Yaffe K., \& Covinsky K., (2002): Cognitive Impairment, Depressive Symptoms, and Functional Decline in Older People, J Am Geriatr Soc.;50(6): Pp. 1045-50.

16. Miller C., (2009): Nursing for Wellness in Older Adult, 5th edition, Chapter 11, p.p. 192, 196, chapter 14, Pp. 273-280

17. Ong S., Cheung C., Li X., Lamoureux E., Ikram M., Ding J., Cheng C., Haaland B., Saw S., Venketasubramanian N., Chen C., \& Wong T., (2012):Visual impairment, age-related eye diseases, and cognitive function: the Singapore Malay Eye study. Arch Ophthalmol.; 130(7): Pp. 895-900.

18. Perel-Levin S., (2008): Discussing Screening for Elder Abuse at Primary Health Care level, Who, Aging And Life Course.

19. Shehatah A., El-Okda E., \& Rabie M., (2009): Prevalence of Depression and Association of Cognitive Impairment in Elderly in Suburban Community in Egypt Current Psychiatry; Vol. 16 No.2: Pp. 192-199).

20. Sweed H., \& Elawam A., (2010): Cognitive Impairment among Residents of Elderly Homes In Cairo, Egypt, Middle East Journal OF Psychiatry And Alzheimers, Volume 1, Issue 1.

21. Umegaki H., Iimuro S., Shinozaki T., Araki A., Sakurai T., Iijima K., Ohashi Y., \& Ito H., (2012): Risk factors associated with cognitive decline in the elderly with type 2 diabetes: baseline data analysis of the Japanese Elderly Diabetes Intervention Trial. Geriatr Gerontol Int.; 12 Suppl 1: Pp. 103-9.

22. Verghese J., Lipton R., Katz M., Hall C., Derby C., Kuslansky G., Ambrose A., Sliwinski M., \& Buschke H., (2003): Leisure Activities and the Risk of Dementia in the Elderly, N Engl J Med; Pp. 348:2508-2516.

23. Wu M., Lan T., Chen C., Chiu H., \& Lan T., (2011): Socio-demographic and health-related factors associated with cognitive impairment in the elderly in Taiwan BMC Public Health, 11:22

24. Zaitoun A., Sarhan A., Selim A., \& Mousa G., (2008): Epidemiological Study of Dementia after Retirement, Egypt J. Neurol. Psychiat. Neurosurg., 45(1): Pp. 65-74.

25. Zhuang J., Wang G., Cheng Q., Wang L., Fang R., Liu L., Xiong R., Zhang Y., Gui Y., Kang W., Tang H., \& Chen S., (2012): Cognitive impairment and the associated risk factors among the elderly in the Shanghai urban area: a pilot study from China, Translational Neurodegeneration, 1:22 